\title{
Edukasi Kepemimpinan Berbasis Tradisi Lokal pada Masyarakat Tolaki di Kabupaten Konawe
}

\author{
Nur Alim ${ }^{1}$, Badarwan $^{2}$, Syahrul $^{3}$ \\ ${ }^{1}$ Fakultas Tarbiyah dan Ilmu Keguruan IAIN Kendari \\ Email: nuralimbasri@iainkendari.ac.id \\ ${ }^{2}$ Fakultas Tarbiyah dan Ilmu Keguruan IAIN Kendari \\ Email: badarwan.kdi@gmail.com \\ ${ }^{3}$ Fakultas Tarbiyah dan Ilmu Keguruan IAIN Kendari \\ Email: syahrul.stain@gmail.com
}

\begin{abstract}
Abstrak
Artikel ini bertujuan mendalami edukasi kepemimpinan berbasis budaya lokal pada masyarakat Tolaki, yang meliputi: 1) asal usul kebudayaan Tolaki; 2) nilai-nilai luhur yang dianut orang Tolaki; 3) Pu'utobu sebagai aktor dalam praktik kepemimpinan tradisional orang Tolaki; 4) proses edukasi kepemimpinan berbasis budaya Tolaki. Untuk mendalami keempat aspek tersebut, digunakan pendekatan kualitatif dengan metode etnografi. Pengumpulan data menggunakan teknik wawancara mendalam, pengamatan terlibat, dan studi dokumen. Data yang terkumpul dianalisis melalui tahap analisis domain, analisis taksonomi, analisis komponensial, dan analisis tema budaya. Untuk menjamin keabsahan data, maka dilakukan perpanjangan pengamatan, peningkatan ketekunan, dan trianggulasi. Hasil penelitian menunjukkan bahwa kebudayaan Tolaki memiliki kedekatan dengan kebudayaan-kebudayaan di Indonesia, baik karena asal-usulnya maupun akibat kontak budaya. Karenanya kebudayaan Tolaki memuat nilai-nilai luhur yang bersifat universal, dapat diterima dan dipraktikan oleh berbagai kalangan masyarakat. Dalam konteks kepemimpinan, praktik kepemimpinan tradisional diperankan oleh Pu'utobu, dalam urusan-urusan adat. Tantangannya, edukasi kepemimpinan tradisional orang Tolaki tidak terlembagakan dengan baik.
\end{abstract}

Kata Kunci: Edukasi Kepemimpinan Tradisional, Budaya Tolaki 


\title{
Leadership Education Based on Local Traditions in the Tolaki Community in Konawe District
}

\author{
Nur Alim ${ }^{1}$, Badarwan $^{2}$, Syahrul $^{3}$ \\ ${ }^{1}$ Fakultas Tarbiyah dan Ilmu Keguruan IAIN Kendari \\ Email: nuralimbasri@iainkendari.ac.id \\ ${ }^{2}$ Fakultas Tarbiyah dan Ilmu Keguruan IAIN Kendari \\ Email: badarwan.kdi@gmail.com \\ ${ }^{3}$ Fakultas Tarbiyah dan Ilmu Keguruan IAIN Kendari \\ Email: syahrul.stain@gmail.com
}

\begin{abstract}
This article aims to explore the education of local culturebased leadership in the Tolaki community, which includes: 1) the origins of Tolaki culture; 2) the noble values shared by the Tolaki people; 3) Pu'utobu as an actor in the traditional leadership practices of the Tolaki people; 4) Tolaki's culture-based leadership education process. To explore these four aspects, a qualitative approach with ethnographic methods is used. Data collection uses in-depth interview techniques, involved observations, and document studies. The collected data is analyzed through domain analysis, taxonomic analysis, componential analysis, and cultural theme analysis. To guarantee the validity of the data, an extension of observation is carried out, increased perseverance, and triangulation. The results showed that Tolaki culture has a closeness to cultures in Indonesia, both because of its origins and cultural contact. Therefore Tolaki culture contains noble values that are universal, can be accepted and practiced by various groups of people. In the context of leadership, traditional leadership practices are played by Pu'utobu, in customary matters. The challenge is that the traditional leadership education of the Tolaki people is not well institutionalized.
\end{abstract}

Keywords: Traditional Leadership Education, Tolaki Culture 


\section{Pendahuluan}

Diskursus kepemimpinan membentang sepanjang sejarah manusia. Paling tidak dalam kepercayaan agama semitik, proses penciptaan manusia adalah dalam rangka menjalankan misi kepemimpinan (khalifah). Evolusi sejarah kemanusiaan pada saat beriringan juga menggambarkan evolusi kepemimpinan. Kehidupan bersuku-suku pada masa belajar berserikat oleh manusia, melahirkan konsep kepemimpinan primus inter pares, suatu bentuk kepemimpinan yang menyandarkan segala kualitas terbaik pada seseorang ${ }^{1}$. Tradisi ini terus berlanjut hingga digantikan oleh persekutuan yang lebih luas karakteristik komunitasnya, seperti klan, kerajaan, hingga negara bangsa.

Meskipun berbagai etnik dunia telah menyerap model kepemimpinan mutakhir, misalnya pemimpin yang dilahirkan dari musyawarah ataupun demokrasi, tetapi nilai-nilai kepemimpinan berbasis etnik masih tetap terpelihara. Meskipun tidak lagi massif, tetapi di masyarakat Tolaki di Kabupaten Konawe, proses seleksi kepemimpinan pada berbagai level masih menimbang aspek-aspek tradisi. Pergantian kepemimpinan politik misalnya, disamping melihat kompetensi dan reputasi, para tetua adat akan membuka lontara yang berisi catatan kukuaha (silsilah/nasab) para calon pemimpin. Dalam konteks ini orang Tolaki memercayai konsep kepemimpinan berdasarkan keturunan ${ }^{2}$.

Kepercayaan bahwa kepemimpinan itu berdasarkan pada bibit tidak hanya dianut secara sepihak oleh keturunan bangsawan. Masyarakat Tolaki di Konawe khususnya masih memercayai bahwa seseorang yang merintis karir sebagai pemimpin negeri, jika memiliki garis kebangsawanan yang kuat, suatu saat akan momboindi wonua (memimpin negeri). Tentu saja masyarakat memiliki mekanisme seleksi sendiri terhadap para calon pemimpin, melalui kriteria-kriteria penunjang, seperti jenjang pendidikan dan hubungan dengan masyarakat. Pada kasus pergantian kepemimpinan anyar di Konawe,

1 Pemilihan berdasarkan kompetensi fisik, psikis, bahkan magis dapat ditelusuri dalam diskursus sosiologi, misalnya oleh Kamanto, S. (2004). Pengantar sosiologi. Lembaga Penerbit Fakultas Ekonomi Universitas Indonesia. Jakarta. Juga oleh Soejono, S. (1990). Sosiologi Suatu Pengantar. Jakarta, Rajawali Pers..

2 Bandingkan dengan Yukl, G. (1981). Leadership in Organizations, 9/e. Pearson Education India. 
nampaknya hubungan dengan masyarakat ditambah kekuatan mesin politik menjadi senyawa kuat lahirnya pemimpin baru.

Persoalan hubungan pemimpin dengan masyarakat, ataupun hubungan sesama manusia secara luas adalah persoalan yang sangat penting dalam sosiologi orang Tolaki. Saramase adalah istilah yang kerap dikaitkan untuk perilaku seseorang yang hangat, terbuka, toleran, senang berbagi, peduli, dan menjaga silaturrahim. Perilaku demikian akan membangun citra diri seorang calon pemimpin, bahwa ia genuine berasal dari generasi bangsawan yang layak memimpin.

Karakterisktik lain yang melekat prinsip kepempimpinan orang Tolaki adalah merou ${ }^{3}$ dan kohanu ${ }^{4}$. Kesantunan atau merou adalah penanda kemuliaan seseorang dalam berhubungan dengan sesama manusia. Sedangkan kohanu adalah komitmen etik orang Tolaki dalam menjaga diri dari perbuatan-perbuatan tercela. Idiom-idiom etik itu dibingkai dalam falsafah morini mbu'u mbundi monapa mbu'u ndawaro ${ }^{5}$, suatu gambaran tentang rasa terdalam dari orang Tolaki yang penuh kesejukan, kedamaian, keterbukaan, persaudaraan, mengayom, dan memberi penghidupan bagi semesta.

Perubahan waktu yang sangat cepat, pada saat yang sama juga menggeser kekuatan tradisi, termasuk nilai-nilai luhur yang hidup pada orang Tolaki. Beberapa problem yang melilit tokoh-tokoh Tolaki tentu menjadi pertanyaan tentang beberapa problem yang melilit tokoh-tokoh Tolaki ${ }^{6}$, mengundang pertanyaan "apakah nilai-nilai luhur ke-Tolakian telah memudar" dalam praktik kehidupan orang Tolaki?. Ataukah nilai-nilai luhur itu telah dikalahkan oleh zaman baru dengan spirit hedonisme-permisivisme?. Dalam bincang keseharian, nilai-nilai luhur di atas sesungguhnya masih melekat kuat dalam memori orang Tolaki. Mungkin saja problemnya adalah

${ }^{3}$ Tulung, G. J. Ungkapan Bermakna Budaya dalam Adat Perkawinan Suku Tolaki di Sulawesi Tenggara Kusnan Dr. Leika kalangi, MS.

${ }^{4}$ Melalatoa, M. Y. (1995). Ensiklopedi Suku-Suku Bangsa Di Indonesia.

5 Fauzi sedikit memberi gambaran tentang falsafah morini mbu'u mbundi monapa mbu'u ndawaro dalam konteks persentuhan orang Tolaki dengan etnik lain di Putemata Kolaka Timur. Lihat Fauzi, I. (2018). Masyarakat Majemuk dan Dinamika Pendidikan Keagamaan (Kajian di Desa Putemata, Kolaka Timur). Shautut Tarbiyah, 24(1), 73-90.

${ }^{6}$ Lihat https://www.bbc.com/indonesia/indonesia-43554605. Lihat pula https://www.merdeka.com/peristiwa/wali-kota-kendari-dan-ayahnya-didakwaterima-suap-rp-28-m.html. 
menurunkannya melalui proses edukasi, sehingga mewujud menjadi perilaku. Tulisan ini adalah hasil penelusuran mendalam tentang nilainilai dalam tradisi orang Tolaki, yang turut mewarnai praktik-praktik kepemimpinan. Proses asosiasi nilai-nilai tradisi dengan praktik kepemimpinan menjadi sorotan utama kajian ini, apakah bersifat kultural atau telah memiliki desain besar.

\section{Metode}

Penelitian ini bertujuan mendalami pandangan orang Tolaki tentang mombulei wопиа, bagaimana mombulei wопиа dipraktikkan dalam peran-peran kepemimpin orang Tolaki kekinian, relasi mombulei wопиа dengan falsafah kohanu dalam praktik kepemimpinan tradisional orang Tolaki; praktik kepemimpinan orang Tolaki menunjukkan jarak dengan nilai-nilai luhur etniknya. Penelitian ini juga diharapkan memberi manfaat dalam beberapa hal: 1) membuka pemahaman tentang prinsip pengelolaan organisasi berdasarkan tradisi lokal; 2) melakukan revitalisasi norma-norma tradisional yang relevan dengan praktik kepemimpinan kekinian; 3) melakukan reproduksi gagasan tentang sistem nilai orang Tolaki; 4) melakukan edukasi tentang nilai-nilai dalam tradisi orang Tolaki yang dapat menunjang kerja-kerja kepemimpinan.

Penelitian ini menggunakan kualitatif dengan metode ethnografi, suatu bentuk pendalaman latar sosial dengan memotret kebiasaan-kebiasaan manusia yang hidup dalam suatu komunitas ${ }^{7}$. Lukisan tentang situasi sosial itu dikonstruksi oleh peneliti hingga sampai ke tingkat makna (meaning) ${ }^{8}$. Data yang dihasilkan dalam bentuk data primer, yang diperoleh dari hasil wawancara dan pengamatan mendalam. Sedangkan data sekunder diperoleh melalui studi dokumentasi. Sumber data penelitian ini mencakup tokoh-tokoh masyarakat Tolaki, pemimpinan daerah, dan masyarakat.

Proses pemerolehan data dilakukan dengan melalui wawancara, pengamatan terlibat dan studi dokumentasi. Wawancara dilakukan pada tokoh-tokoh masyarakat Tolaki, pemimpinan daerah, dan masyarakat untuk mendapatkan data tentang pandangan orang Tolaki tentang falsafah mombulei wonua. Observasi dilakukan

7 Spradley, J. P. (2016). The ethnographic interview. Waveland Press.

8 Moleong, J. Lexy. (2014), Metodologi Penelitian Kualitatif, Bandung: PT. Remaja Rosdakarya. 
terhadap keseharian orang Tolaki yang terlibat secara dekat dengan praktik kepemimpinan, edukasi tentang nilai luhur orang Tolaki, dan hubungan sistemik antar nilai-nilai luhur orang Tolaki. Studi dokumen dilakukan untuk mendalami naskah-naskah, jurnal, buletin, artefak kebudayaan Tolaki, terutama yang relevan dengan masalah kepemimpinan.

Data yang terkumpul dianalisis dengan menggunakan empat langkah dari Spradley, yakni: analisis domain, analisis taksonomi, analisis komponensial, dan analisis tema budaya ${ }^{9}$. Jaminan keabsahan data diperoleh melalui proses pemeriksaan keabsahan data, dengan menggunakan beberapa cara, yakni: Trianggulasi, member check, perpanjangan pengamatan, dan peningkatan ketekunan ${ }^{10}$.

\section{Hasil Penelitian}

\section{A. Asal-Usul Kebudayaan Tolaki}

Kabupaten Konawe adalah salah satu daerah administratif di wilayah daratan Sulawesi Tenggara yang didiami oleh Orang Tolaki. Reformasi yang menuntut penerapan otonomi daerah menyebabkan terbentuk daerah-daerah pemekaran baru di daratan Konawe, yang hari ini menjadi daerah administratif otonom seperti: Kota Kendari, Kabupaten Konawe Selatan, Kabupaten Konawe Utara, dan Kabupaten Konawe Kepulauan.

Secara antropologis, orang Tolaki memiliki kedekatan kekerabatan dengan suku-suku di Sulawesi Tengah, terutama dalam rumpun Bungkulaki. Sumber-sumber lisan dan legenda juga menyebutkan hubungan kekerabatan orang Tolaki dengan orang Toraja dan Luwu. Lebih jauh lagi adalah nenek moyang orang Tolaki yang berasal dari Tiongkok, yang tercermin dalam istilah tolahianga, yaitu asal muasal orang Tolaki dari negeri langit ${ }^{11}$.

Perjumpaan orang Tolaki dengan agama Islam menyebabkan perluasan kekerabatan dengan etnik-etnik terdekat di Sulawesi Tenggara, seperti: Buton, Muna, dan Bugis. Sedangkan yang cukup jauh adalah Ternate. Raja Lakidende II yang bergelar sangia ngginoburu atau raja yang pertama kali dikuburkan, sebelum

${ }^{9}$ Spradley, J. P. (2016). Participant observation. Waveland Press.

${ }^{10}$ Sugiyono, P. (2005). Memahami penelitian kualitatif. Bandung: Alfabeta.

11 Melamba, B. (2013). Tolaki: sejarah, identitas, dan kebudayaan. Penerbit Lukita. 
dinobatkan sebagai raja, ia menuntut ilmu agama Islam di kesultanan Buton. Hubungan dengan kesultanan Buton tetap terpelihara hingga Lakidende menjadi raja, yang menandai islamisasi di tanah Tolaki. Kerajaan Tiworo (Muna) ditugaskan oleh Kesultanan Buton membantu proses pengajaran agama Islam pada masyarakat Tolaki ${ }^{12}$.

Secara kultural, orang Tolaki memiliki identitas kebudayaan sendiri yakni kebudayaan Tolaki. Simpul dari kebudayaan Tolaki adalah Kalo Sara yang disimbolkan dalam bentuk anyaman rotan yang dibuat melingkar. Kalo Sara merupakan simpul ke-Tolakian, menyangkut aspek individual, komunal, fisik, psikis, religiusitas, seni bahkan magis ${ }^{13}$.

\section{B. Nilai-Nilai Luhur dalam Kebudayaan Tolaki}

Dalam Masyarakat Tolaki filsafat kehidupan berakar pada ungkapan Inae kosara iee pinesara; inae liasara iee pinekasara (siapa yang tahu adat akan dihormati; siapa yang melanggar adat akan dikasari/tidak akan dihormati). Filsafat ini kemudian tersimpul dalam simbol kalosara yang mengatur tata hubungan antar manusia dan lingkungannya ${ }^{14}$. Orang yang patuh pada adat/norma adalah orang beradab atau disebut kosara, orang seperti ini akan dihormati dan disegani oleh masyarakat. Orang yang menolak adat disebut matesara (mati adat), dan orang yang melampauhi ketentuan adat disebut liasara $^{15}$.

Dalam hubungan antar anggota masyarakat ini, terdapat unsurunsur yang mengandung nilai filsafat tinggi. Mereka menjadikannya sebagai tongkat pegangan untuk menjalani kehidupan sehari-hari. Adapun jenis budaya hasil karya dan cipta yang mempunyai nilai sosial tinggi dan merupakan perwujudan karakter positif yang lahir dari etnopedagogik melalui media kalosara menurut Hafid antara lain:

12 lihat Syahrul, S. (2017). Tanggung Jawab Sosial Pesantren: Studi pada Pondok Pesantren Al Munawwarah Pondidaha, Konawe. Shautut Tarbiyah, 23(2), 120-134

13 Tarimana, A. (1989). Kebudayaan Tolaki (No. 3). Balai Pustaka.

${ }^{14}$ Tamburaka, R. E. (2010). Sejarah Sulawesi Tenggara dan 45 tahun Sultra membangun. Unhalu Press.

${ }^{15}$ Al-askur, Arsamid. (2015). Kearifan Lokal tentang Tandua-Anandulura dan Sala Anggo. Kendari: Barokah Raya. 
1. Kohanu. Kohanu, sering disebut dengan budaya malu. Kohanu, merupakan sistem pertahanan moral bagi diri sendiri, misalnya ada orang yang dikatakan malas bekerja, maka selanjutnya mereka menerapkan budaya kohanu ini dengan cara lebih tekun dan rajin dalam bekerja, sehingga sebutan sebagai pemalas akan hilang dari dirinya, berganti dengan sebutan pekerja keras yang rajin dan tekun. Secara tidak langsung budaya ini mengajak setiap orang untuk selalu memaksimalkan tenaga maupun pikiran yang dimilikinya untuk memajukan dia sendiri atau anggota kelompok yang lain. 16

2. Merou. Merou, adalah budaya yang mengajak orang untuk selalu mengedepankan sikap sopan dan santun dalam pergaulan, serta mau memberikan rasa hormat bagi semua anggota masyarakat Tolaki maupun orang lain.

3. Samaturu. Samaturu, merupakan salah satu budaya yang mengutamakan hidup untuk selalu menjalin persatuan, suka menolong orang lain yang sedang membutuhkan pertolongan dengan senang hati. Ini juga merupakan wujud dari gotong royong yang menjadi pandangan hidup utama dari Suku Tolaki.

4. Taa Ehe Tinua-Tuay. Taa ehe tinua-tuay,merupakan ajakan untuk selalu merasa bangga karena menjadi bagian dari Masyarakat Tolaki. Sesungguhnya budaya ini menjadi bagian dari kohanu, namun karena adanya suatu perbedaan yang bersifat mengutamakan kemandirian, maka budaya yang satu ini selanjutnya dipisah menjadi budaya sendiri.

5. O'Sapa. Istilah o'sapa ialah semacam aturan-aturan klasik yang mengatur hubungan hukum antara manusia dengan hewan. Hubungan-hubungan itu timbul manakala manusia melakukan pemburuan (berburu) terhadap binatang liar seperti kerbau, rusa dan anoa, dengan menggunakan tombak, menggunakan anjing, perangkap, dan alat-alat penangkap lainnya, Aturan-aturan o'sapa itu berwujud ketaatan/kepatuhan setiap orang/pemburu mengambil bagian dari jerih payah yang tidak menyalahi ketentuan o'sapa, misalnya: Apabila binatang buruan itu mati berkat bantuan

${ }^{16}$ Hafid, Anwar. (2015). "Analisis Fungsi Kalosara Sebagai Media Etnopedagogi dalam Pengembangan Karakter Bangsa di Sulawesi Tenggara". Makalah Disajikan Pada Seminar Nasional "Meretas Strategi Pembelajaran Inovatif Berbasis Seni Budaya", di Kendari. 
peralatan tombak dan anjing, maka bagian tertentu dari daging kerbau atau rusa itu, harus diberikan kepada anjing (pemilik anjing) dan tombak (yang menombak pertama) diluar dari bagian tertentu yang biasa diberikan/diambil/dikuasai si pemburu (3/4 bagian) dan bagian penguasa wilayah untuk daging dan tulang-tulang tertentu. Apabila binatang, tersebut adalah binatang liar, tetapi bekas binatang peliharaan, maka aturan pembagiannya telah tertentu pula bagi pemburunya, untuk anjing, untuk tombak dan untuk penguasa wilayah/puutobu atau kepala kampung. Aturan-aturan pembagian itulah disebut $O$ 'sapa, yang menurut kaidah hidup bermasyarakat harus dipatuhi oleh anggota Masyarakat Tolaki termasuk Penguasa/Raja. Bila aturan hukumnya tidak dijalankan, maka dapat menimbulkan dampak negatif terhadap kehidupan masyarakat dan negeri.

6. O'wua Istilah O'wиa merupakan seperangkat aturan/ketentuan hukum yang mengatur tata-cara bercocok tanam, merambah hutan, menanam padi, dan aturan-aturan ini harus ditaati oleh semua Suku Tolaki termasuk Penguasa/Raja. Apabila dilanggar maka negeri/penduduk dapat menderita kekurangan pangan mengalami musim paceklik, ini suatu hal yang sangat ditakuti oleh Suku Tolaki.

7. O'lawi. Istilah o'lawi ialah seperangkat aturan dasar tentang pemberian upah, imbalan jasa, pembagian kerja dari seorang majikan pemilik kebun padi atau pemilik pohon sagu, atau pemilik pohon buah-buahan yang didikerjakan oleh seseorang atau beberapa orang pekerja upahan (toono mehawe, pasaku, pa mone dan lain-lain) dengan upah atau bagian-bagian tertentu. Ketentuan pembagian tersebut harus dipatuhi dengan sadar oleh semua orang termasuk penguasa/mokole.

8. O'liwi. O'liwi ialah seperangkat pesan, nasihat dan petunjuk hidup yang ditinggalkan/diwasiatkan seseorang untuk diikuti oleh anak cucu /generasi berikut dari para leluhur, secara turun-temurun terutama dalam hal ini dapat disamakan dengan Yurisprudensi artinya putusan hakim tertinggi yang telah berlaku tetap dan dapat dicontoh oleh hakim-hakim berikutnya dalam perkara yang sama maupun lainnya. ${ }^{17}$

${ }^{17}$ Hafid, Anwar. (2012). Kalosara Sebagai Instrumen Utama Dalam Kehidupan Sosial Budaya Suku Tolaki di Sulawesi Tenggara. Makalah Disajikan 


\section{Pu'utobu Sebagai Aktor Kepemimpinan Tradisional}

Jika dilihat dalam setiap kehidupan masyarakat suku Tolaki, bahwa segala aktivitas yang berhubungan dengan tatanan kehidupan sosial akan terlihat peran para pemimpin tradisional seperti Pu`utobu. Peran Pu`utobu dalam kehidupan masyarakat suku Tolaki sangatlah penting, mengingat pu`utobu merupakan sentral dalam kepemimpinan tradisional, yang memiliki peran penting dalam menyelesaikan segala bentuk permasalahan dalam masyarakat secara umum.

Mengingat peran Pu`utobu sangat penting maka segala permasalahan yang dihadapi bagi setiap anggota masyarakat suku Tolaki dapat diselesaikan dengan melibatkan para tokoh adat yang lain seperti Tolea/Pabitara. Peran tersebut dijalankan secara baik dan maksimal demi terciptanya kondisi kehidupan yang kondusif dalam masyarakat.

Pu`utobu dalam menjalankan kepemimpinan tradisional diharapkan dapat menyelesaikan permasalahan yang terjadi dalam kehidupan masyarakat secara adil dan bijaksana atau tidak melakukan tindakan yang disebut Mosule $O$ 'Sara, artinya memutuskan atau mengambil keputusan suatu permasalahan secara keliru atau bertentangan nlai-nilai adat yang terkandung dalam konsep Kalo Sara. Dengan demikian, seorang Pu'utobu mampu penyelesaikan segala polemik kehidupan masyarakat secara tepat dengan menganut nilainilai asas keadilan. Bagi setiap suku Tolaki wajib baginya untuk memahami secara benar tentang manfaat Kalo Sara dalam kehidupan sehari-hari, baik pemimpin tradisional maupun pemerintah setempat. Sebab interaksi sosial semua elemen tak akan terhindarkan, mengingat masyarakat suku Tolaki memiliki budaya atau tradisi adat istiadat dalam menanggulangi segala permasalahan dalam masyarakat.

dalam Prakongres Kebudayaan Indonesia di Jakarta, Tanggal 27-29 November 2012. 
Gambar 1. Struktur Organisasi Puutobu

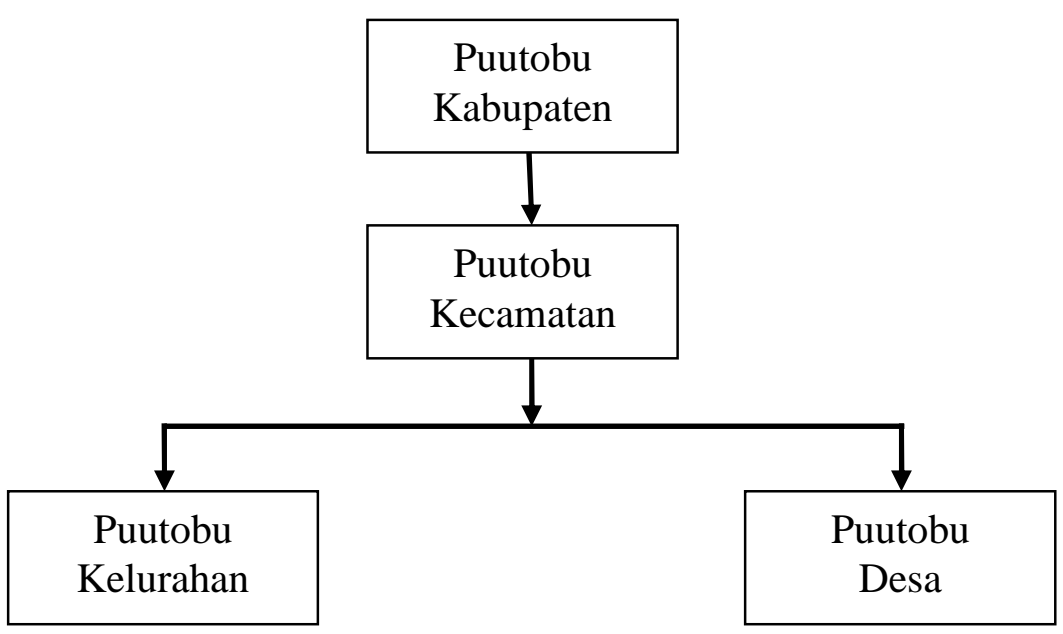

\section{Edukasi Kepemimpinan Berbasis Budaya Tolaki}

Secara reguler, pemerintah Kerajaan Konawe dahulu kala telah mendirikan suatu lembaga pendidikan pengkaderan calon pemimpin yang bernama Inae Sinumo yang berkedudukan di Abuki mirip dengan fungsi Sekolah Tinggi Pemerintahan Dalam Negeri (STPDN). Melalui lembaga Inae Sinumo ini diharapkan internalisasi nilai-nilai kalosara dapat dipertahankan dan dikembangkan oleh seluruh lapisan masyarakat, yang senantiasa didukung dan dipelopori oleh pemimpin yang benar-benar memahami dan berkomitmen mengembangkan kalosara dalam kehidupan masyarakat Tolaki ${ }^{18}$.

Dalam konteks kekinian orang Tolaki, lembaga pendidikan calon pemimpin tidak lagi diteruskan. Inae Sinumo, sebagaimana disebutkan di atas, hanya menjadi tradisi yang hidup dalam budaya tutur masyarakat. Tidak dapat lagi ditemukan bentuk-bentuk yang lebih praktik tentang lembaga pendidikan tersebut. Meskipun demikian, informasi ini menunjukkan bahwa di masa lalu orang Tolaki telah memiliki lembaga pembibitan calon pemimpin yang dilaksanakan secara reguler. Masalahnya, tidak ada kesinambungan program pendidikan calon pemimpin yang dilakukan generasi yang datang berikutnya.

18 Suardika, I. K. (2017). Kalosara di Kalangan Masyarakat Tolaki di Sulawesi Tenggara. Mudra Jurnal Seni Budaya, 32(2). 


\section{Pembahasan}

Takdir manusia yang selalu hidup dalam persekutuanpersekutuan menyebabkan keterikatannya dengan persoalan kepemimpinan. Sehingga menjadi hukum sosial bahwa persoalan kepemimpinan akan selalu membentuk kutub magnet. Persoalanpersoalan keorganisasian yang menyangkut hajat hidup orang banyak akan selalu ditimpakan pada seorang pemimpin. Perwujudan primus inter pares dalam kehidupan sosial manusia turut mengalami perubahan-perubahan, namun esensi tanggung jawab kepemimpinan tidak pernah berubah.

Ketika secara massif para pemimpin daerah, wakil rakyat, petinggi partai, pada berbagai level menjadi pesakitan di Komisi Pemberantasan Korupsi (KPK), masyarakat menjadi mafhum bahwa kita sedang menghadapi masalah-masalah kepemimpinan. Demikian pula persoalan pembangunan dan kesejahteraan selalu menunjuk pada optimalisasi peran-peran kepemimpinan.

Tawaran-tawaran model kepemimpinan modern telah diadopsi dalam penyelenggaraan lembaga di berbagai bidang. Demikian juga agama memberikan perspektif moral tertinggi tentang perilaku kepemimpinan sebagaimana dicontohkan para pesuruh Tuhan. Namun, pendekatan kepemimpinan modern plus agama sepertinya belum kuat membendung arus hedonisme di ranah kepemimpinan. Bahkan "para pesakitan" itu adalah keluaran sekolah-sekolah modern, dalam dan luar negeri, dan juga banyak paham persoalan moral keagamaan. Ruang ini ingin diisi pula dari sisi sumbangan tradisi lokal dalam rangka menguatkan praktik kepemimpinan. Sehingga tidak hanya modernitas plus agama, tetapi juga tradisi lokal. Dalam konteks inilah kajian ini penting dikemukakan.

\section{Kebudayaan Tolaki: Metamorfosa identitas}

Eksistensi orang Tolaki hingga saat ini merupakan potret perjalanan panjang sebuah etnik dalam menjadi entitas sosial tertentu. Mereka adalah komunitas yang melakukan migrasi dari satu wilayah ke wilayah lainnya, kemudian menetap, sehingga menciptakan identitas etnik baru. Karenanya, kebudayaan Tolaki dapat dilihat kemiripannya suku-suku tertentu diduga adalah kebudayaan serumpun 
Bungkulaki $i^{19}$. Artinya bahwa, suku Tolaki memiliki ikatan kekerabatan dengan beberapa suku serumpun, yang dapat berarti bahwa sejak awal orang Tolaki menyadari keberadaannya sebagai bagian dari mata rantai sosial. Karenanya, orang Tolaki memiliki tanggung jawab dalam mewujudkan integrasi sosial. Hal ini sangat diperlukan dapat kehidupan serba majemuk saat ini $^{20}$.

Asal usul orang Tolaki yang berasal dari langit, atau negeri jauh menunjukkan keagungan karakter mereka. Sebab langit menunjukkan ketinggian, yang jika diasosiasikan dengan kehidupan masyarakat maka akan berarti kehidupan yang dipenuhi oleh praktik nilai-nilai luhur, akhlakul karimah. Hal ini tergambar dalam adagium inae konasara iye pinesara, inae lia sara iye pinekasara, ataupun dalam frasa morini mbu'u mbundi monapa mbu'bu ndawaro. Dalam konteks kekinian yang sedang menggalakkan pendidikan karakter, penting memerhatikan fakta-fakta antropologi tersebut ${ }^{21}$.

\section{Menguatkan Kembali Fungsi Kepemimpinan Tradisional}

Berbagai etnik dunia mengenalkan ragam kepemimpinan khas etnik masing-masing. Di Indonesia, masyarakat Kajang di Sulawesi Selatan memegang kepemimpinan ammatoa, yang juga dianggap sebagai sistem sosial orang Kajang ${ }^{22}$. Di daerah priangan, kaum Menak dianggap menciptakan suatu bentuk kepemimpinan tradisional, terutama komunitas yang dikenal sebagai Menak Lama, yaitu komunitas bangsawan yang memiliki kekuasan karena berasal dari keturunan para pemimpin daerah, seperti bupati. Kegemilangan kaum Menak dimulai pada abad ke-17 karena dukungan kolonial. Perubahan zaman, peralihan dari pemerintah kolonial Belanda kepada pemerintah NKRI menyebabkan pergeseran eksistensi kaum Menak. Posisi kaum Menak tidak lagi secara monolitik dialamatkan kepada para keturunan

19 Melamba, B. (2013). Tolaki: sejarah, identitas, dan kebudayaan. Penerbit Lukita.

20 Ar, E. H. (2013). Integrasi Sosial Dalam Masyarakat Multi Etnik. Walisongo: Jurnal Penelitian Sosial Keagamaan, 21(1), 191-218.

${ }^{21}$ Istiawati, N. F. (2016). Pendidikan karakter Berbasis Nilai-nilai Kearifan lokal Adat AMMATOA dalam menumbuhkan karakter konservasi. CENDEKIA: Journal of Education and Teaching, 10(1), 1-18.

22 Hijjang, P. (2014). Pasang dan Kepemimpinan Ammatoa: Memahami Kembali Sistem Kepemimpinan Tradisional Masyarakat Adat dalam Pengelolaan Sumberdaya Hutan di Kajang Sulawesi Selatan. Antropologi Indonesia. 
pejabat, tetapi digantikan oleh kaum Menak Baru yang tampil dalam strata tinggi masyarakat Priangan karena pendidikan dan kompetensi ${ }^{23}$. Sementara itu di Minangkabau sejak lama telah menerapkan sistem kemasyarakatan Bodhi Chaniago dan Koto Piliang, yang secara non formal membentuk kepemimpinan adat masyarakat Minang. Kondisi ini tidak lagi berjalan semestinya ketika kolonialisme menginjakkan kaki di ranah minang ${ }^{24}$.

Weber memetakan tipologi kepemimpinan menjadi tiga, yaitu "tradisional, legal-rasional, dan kharismatik ${ }^{25}$. Sebagai seorang sosiolog, Weber banyak mendatangi komunitas dan etnik di berbagai tempat, sehingga membuat penggambaran besar tentang tipologi kepemimpinan yang diterapkan oleh kebanyakan umat manusia ${ }^{26}$.

Lebih jauh Weber melihat kepemimpinan tradisional sebagai sebuah orde sosial yang berpegang pada kebiasaan-kebiasaan lama, dalam hal ini adat ${ }^{27}$. Koentjaraningrat melihat bahwa kebiasaan lama yang menyandarkan kepercayaan pada preferensi personal menghasilkan satu model hubungan pemimpin dengan pengikut yakni kesetiaan. Model ini berbeda secara tegas dengan kepemimpinan legal-rasional yang berpedoman pada peraturan perundangan tertulis. Sepertinya kepemimpinan tradisional dalam versi lebih dekat dengan kepemimpinan kharismatik yang memberikan kepercayaan kepada seseorang untuk memimpin karena dianggap memiliki kekuatan transeden $^{28}$. Bahkan kepemimpinan yang menyatukan aspek tradisional dan magis dapat ditemukan dalam diri Kyai Banten, yang oleh Juhana disebut sebagai kepemimpinan Kyai-Jawara ${ }^{29}$.

${ }^{23}$ Herlina, N. (1997). kehidupan kaum menak Priangan 1800-1942 (Doctoral dissertation, Universitas Gadjah Mada).

${ }^{24}$ Fatimah, S. (2011). Kepemimpinan Tradisional Masyarakat Minangkabau pada Masa Pendudukan Jepang. TINGKAP, 7(1).

${ }^{25}$ Weber, Max. (2009). The theory of social and economic organization. Simon and Schuster.

${ }^{26}$ diantaranya adalah Weber, Max. (2013). From Max Weber: essays in sociology. Routledge; dan Weber, Max. (1993). The sociology of religion. Beacon Press; serta Weber, Max. (1993). Basic concepts in sociology. Citadel Press.

${ }^{27}$ Weber, Ibid

28 Fatimah, S. (2011). Kepemimpinan Tradisional Masyarakat Minangkabau pada Masa Pendudukan Jepang. TINGKAP, 7(1).

${ }^{29}$ Juhana, Ade. (2007). Kepemimpinan Kiai-Jawara: Relasi Kuasa dalam Kepemimpinan Religio-Magis di Pedesaan Banten, Jakarta: Badan Litbang \& Diklat Departemen Agama RI. 


\section{Edukasi Kepemimpinan Tradisional dan Arus Perubahan}

Telah dijelaskan sebelumnya bahwa kepemimpinan tradisional di Minangkabau mengalami pergeseran bahwa rusak akibat serbuan kolonial asing ${ }^{30}$. Kondisi ini pun dialami oleh daerah lain di nusantara. Jikapun tetap bertahan, maka kepemimpinan tradisional harus tunduk pada kemauan kolonial, sebagaimana fenomena kaum Menak di Priangan $^{31}$. Serbuan modernitas juga semakin menggoyang posisi kepemimpinan tradisional yang merasa telah mapan dan tidak ingin berubah. Hal ini sesuai ramalan Weber di atas, tentang kehadiran masyarakat terdidik yang menginginkan kepemimpinan yang dilandasi oleh rasionalitas, memiliki pedoman tertulis yang diundangkan ${ }^{32}$.

Meskipun demikian, era postmodern pun tiba dan melakukan gugatan-gugatan atas capaian-capaian modernitas. Keserakahan, hedonisme, hingga permisifisme yang dituduhkan sebagai kegagalan modernitas, seakan menjadi angin segar bagi tampilnya kembali kepemimpinan tradisional. Tidak lagi dalam bentuk purba, tetapi penyerapan terhadap nilai-nilai luhurnya. Gagasan untuk merevitalisasi model kepemimpinan berbasis budaya lokal adalah ikhtiar mendekatkan kembali praktik kepemimpinan ke akar tradisi yang penuh keluhuran, menjaga moral, dan dapat menunjang pengembangan peradaban.

\section{Kesimpulan dan Saran}

Kebudayaan Tolaki merupakan gambaran dari nilai-nilai, asumsi dasar, dan jejak-jejak kehidupan orang Tolaki. Kalo Sara menjadi simbol pertemuan dari semesta kehidupan orang Tolaki. Nilai-nilai luhur yang dianut orang Tolaki berifat universal, dimana secara substantif dapat ditemui dalam kebudayaan pada etnik lainnya, tetapi diungkapkan dengan bahasa yang berbeda. Kemampuan bertahan masyarakat Tolaki dan kebudayaannya hingga kini, sangat mungkin karena sifat universal tersebut. Secara alamiah, segala segi kehidupan orang Tolaki terikat dan terhubung dengan nilai-nilai universal budayanya. Dalam konteks kepemimpinan, ungkapan nilainilai luhur orang Tolaki akan semakin nampak, mulai dari tutur para

30 Fatimah, S. (2011). Kepemimpinan Tradisional Masyarakat Minangkabau pada Masa Pendudukan Jepang. TINGKAP, 7(1).

${ }^{31}$ Herlina, Nina, and A. Sartono Kartodirdjo, op.cit

${ }^{32}$ Weber, op.cit. 
pejabat hingga penerapannya dalam hubungan pimpinan dengan bawahan. Secara formal, praktik kepemimpinan tradisional orang Tolaki hanya nampak dalam urusan adat an sich yang dilaksanakan oleh para Pu'utobu mulai dari tingkat kabupaten hingga kelurahan dan desa. Namun demikian, secara substantif, nilai-nilai luhur ke-Tolakian yang universal itu hidup dalam kesadaran orang Tolaki. Hal ini mewarnai praktik penataan kehidupan orang Tolaki hingga pada level pemerintahan, yang diwujudkan dalam kebijakan pembangunan. Tantangannya adalah proses edukasi budaya Tolaki yang hanya berjalan secara kultural, belum terlembagakan dengan baik.

Sebagai implikasi dari kajian ini, penulis menyarankan perlunya studi lanjut tentang strategi pembangunan berbasis kebudayaan Tolaki di Konawe. Selain itu, perlu dirumuskan konsep edukasi kepemimpinan berbasis kebudayaan Tolaki yang terlembaga secara baik. 


\section{Daftar Pustaka}

Al-askur, Arsamid. (2015). Kearifan Lokal tentang TanduaAnandulura dan Sala Anggo. Kendari: Barokah Raya.

Ar, E. H. (2013). Integrasi Sosial Dalam Masyarakat Multi Etnik. Walisongo: Jurnal Penelitian Sosial Keagamaan, 21(1), 191218.

Fatimah, S. (2011). Kepemimpinan Tradisional Masyarakat Minangkabau pada Masa Pendudukan Jepang. TINGKAP, 7(1).

Fauzi, I. (2018). Masyarakat Majemuk dan Dinamika Pendidikan Keagamaan (Kajian di Desa Putemata, Kolaka Timur). Shautut Tarbiyah, 24(1), 73-90.

Hafid, Anwar. (2015). "Analisis Fungsi Kalosara Sebagai Media Etnopedagogi dalam Pengembangan Karakter Bangsa di Sulawesi Tenggara”. Makalah Disajikan Pada Seminar Nasional "Meretas Strategi Pembelajaran Inovatif Berbasis Seni Budaya", di Kendari.

Herlina, N. (1997). kehidupan kaum menak Priangan 1800-1942 (Doctoral dissertation, Universitas Gadjah Mada).

Hijjang, P. (2014). Pasang dan Kepemimpinan Ammatoa: Memahami Kembali Sistem Kepemimpinan Tradisional Masyarakat Adat dalam Pengelolaan Sumberdaya Hutan di Kajang Sulawesi Selatan. Antropologi Indonesia.

https://www.bbc.com/indonesia/indonesia-43554605. Lihat pula https://www.merdeka.com/peristiwa/wali-kota-kendari-danayahnya-didakwa-terima-suap-rp-28-m.html.

Istiawati, N. F. (2016). Pendidikan karakter Berbasis Nilai-nilai Kearifan lokal Adat AMMATOA dalam menumbuhkan karakter konservasi. CENDEKIA: Journal of Education and Teaching, 10(1), 1-18.

Juhana, Ade. (2007). Kepemimpinan Kiai-Jawara: Relasi Kuasa dalam Kepemimpinan Religio-Magis di Pedesaan Banten, Jakarta: Badan Litbang \& Diklat Departemen Agama RI.

Kamanto, S. (2004). Pengantar sosiologi. Lembaga Penerbit Fakultas Ekonomi Universitas Indonesia. Jakarta.

Melalatoa, M. Y. (1995). Ensiklopedi Suku-Suku Bangsa Di Indonesia.

Melamba, B. (2013). Tolaki: sejarah, identitas, dan kebudayaan. Penerbit Lukita. 
Moleong, J. Lexy. (2014), Metodologi Penelitian Kualitatif, Bandung: PT. Remaja Rosdakarya.

Soejono, S. (1990). Sosiologi Suatu Pengantar. Jakarta, Rajawali Pers.

Spradley, J. P. (2016). The ethnographic interview. Waveland Press.

Spradley, J. P. (2016). Participant observation. Waveland Press.

Suardika, I. K. (2017). Kalosara di Kalangan Masyarakat Tolaki di Sulawesi Tenggara. Mudra Jurnal Seni Budaya, 32(2).

Sugiyono, P. (2005). Memahami penelitian kualitatif. Bandung: Alfabeta.

Syahrul, S. (2017). Tanggung Jawab Sosial Pesantren: Studi pada Pondok Pesantren Al Munawwarah Pondidaha, Konawe. Shautut Tarbiyah, 23(2), 120-134.

Tamburaka, R. E. (2010). Sejarah Sulawesi Tenggara dan 45 tahun Sultra membangun. Unhalu Press.

Tarimana, A. (1989). Kebudayaan Tolaki (No. 3). Balai Pustaka.

Tulung, G. J. Ungkapan Bermakna Budaya dalam Adat Perkawinan Suku Tolaki di Sulawesi Tenggara Kusnan Dr. Leika kalangi, MS.

Weber, Max. (2009). The theory of social and economic organization. Simon and Schuster.

Weber, Max. (2013). From Max Weber: essays in sociology. Routledge.

Weber, Max. (1993). The sociology of religion. Beacon Press.

Weber, Max. (1993). Basic concepts in sociology. Citadel Press.

Yukl, G. (1981). Leadership in Organizations, 9/e. Pearson Education India. 